\title{
An Empirical Look at the Nature Index
}

\author{
Lutz Bornmann* \& Robin Haunschild**
}

* Corresponding author:

Division for Science and Innovation Studies

Administrative Headquarters of the Max Planck Society

Hofgartenstr. 8,

80539 Munich, Germany.

E-mail: bornmann@gv.mpg.de

** Max Planck Institute for Solid State Research

Heisenbergstr. 1,

70569 Stuttgart, Germany.

E-mail: R.Haunschild@fkf.mpg.de 


\begin{abstract}
In November 2014, the Nature Index (NI) was introduced (see http://www.natureindex.com) by the Nature Publishing Group (NPG). The NI is comprised of the primary research articles published in the past 12 months in a selection of reputable journals. Starting from two short comments on the NI (Haunschild \& Bornmann, 2015a, 2015b), we undertake an empirical analysis of the NI using comprehensive country data. We investigate whether the huge efforts of computing the NI are justified and whether the size-dependent NI indicators should be complemented by size-independent variants. The analysis uses data from the Max Planck Digital Library in-house database (which is based on Web of Science data) and from the NPG. In a first step of analysis, we correlate the NI with other metrics which are simpler to generate than the NI. The resulting very large correlation coefficients point out that the NI produces very similar results as simpler solutions. In a second step of analysis, relative and size-independent variants of the NI are generated which should be additionally presented by the NPG. The size-dependent NI indicators favor large countries (or institutions) and the topperforming small countries (or institutions) do not come into the picture.
\end{abstract}




\section{Introduction}

Currently, there exist five major international university rankings worldwide: (1) Academic Ranking of World University (ARWU), (2) Times Higher Education World University Rankings (THE Rankings), (3) QS World University Rankings, (4) Leiden Ranking by the Centre for Science and Technology Studies (CWTS), and (5) SCImago Institutions Ranking. Whereas the first three rankings use very different indicators to rank universities, the last two use a set of bibliometric indicators only. An overview over these (and other university rankings) can be found in several publications: Safón (2013), Dill and Soo (2005), Buela-Casal, Gutiérrez-Martínez, Bermúdez-Sánchez, and Vadillo-Muñoz (2007), Aguillo, Bar-Ilan, Levene, and Ortega (2010), Rauhvargers (2011). These overviews describe - among other things - the different indicators used and compare the ranking results based on the different ranking methods.

In November 2014, the Nature Index (NI) was introduced (see http://www.natureindex.com) (Campbell \& Grayson, 2014). According to Campbell and Grayson (2015) the Nature Publishing Group (NPG) "does not intend the Nature Index to be a ranking and have quite deliberately not referred to it as such anywhere" (p. 1831). However, the NI allows exactly this: a ranking of worldwide institutions and countries based on their publication output in selected journals (see http://www.natureindex.com/country-outputs and http://www.natureindex.com/institution-outputs). Thus, the NI should be discussed against other possibilities of measuring the performance of institutions or countries. The aim of this paper is to empirically study the NI as a new ranking method in more detail and to provide possible improvements. In a first step of analysis, we correlate the NI with other metrics which are simpler to generate than the NI. In a second step, relative and size-independent variants of the NI are generated which should be additionally presented by the NPG. 


\section{The Nature Index}

The NI is comprised of the primary research articles published in the past 12 months in a selection of reputable journals. The list of 68 journals is the result of 68 panelists being asked to name the journals (maximal $n=10$ ) in which they would want to publish their best research articles. Two panel chairs signed off on the final list. A confirmation attempt was made by sending out an online questionnaire to 100,000 scientists in the life, physical, and medical sciences. They also were asked to name their 10 most preferred journals. The panel chairs recorded a response rate of 2.8\%. Overall, Campbell and Grayson (2014) reported "a high degree of convergence between the panel and survey outputs for the most popular journals" (p. S52). The NI contains three quantities: the raw article count (AC), the fractional count (FC), and the weighted fractional count (WFC). The AC is obtained from counting all primary research articles published in the past 12 months in the NI journals. The fractional count weights the individual primary research article according to the number of co-authors (e.g.: if three scientists from the USA and two scientists from Japan published one paper in a NI journal, this paper is counted as $3 / 5$ for the USA and $2 / 5$ for Japan). The WFC is supposed to account for the fact that papers from journals in the field astronomy and astrophysics are approximately five times as numerous as papers from other fields in the NI. Therefore, papers from the field astronomy and astrophysics are weighted with a coefficient of 0.2 .

Recently, we started the discussion about the NI with two comments (Haunschild \& Bornmann, 2015a, 2015b). One of our discussion starters has sparked a reply (Campbell \& Grayson, 2015).

\section{Methods}

On February 10, 2015, we saved the country tables from the NI for the publication period 01 January 2014 - 31 December 2014. In June 2015, the NPG published the NI supplement 2015 including a table with the top 100 countries 
(http://www.nature.com/nature/journal/v522/n7556_supp/full/522S34a.html). The comparison of both tables shows small deviations. For example, in February the USA had an $\mathrm{AC}=26,631$ and in June an $\mathrm{AC}=26,638$. The NPG seems to continuously update their older data. The deviations between both points in time are so small for all countries that we decided to use the data from February. A further advantage of this data is that the FC is included (in the NI supplement table it is not).

Reference data for the full publication output were taken from the in-house database of the Max Planck Society (MPG) based on the WoS and administered by the Max Planck Digital Library (MPDL). Since we do not have reliable data in the database on the institutional, but on the country level, the study focuses on countries. Also, the period of analysis is 01 January 2014 - 31 December 2014.

In this study only countries are considered with at least $n=1000$ papers and an $\mathrm{AC}$ of at least 30. Although the study focusses on one year only (2014), we would like to produce results which can be generalized for neighboring years. In case of small publication sets for a country, large annual variations of indicator values can be expected (Levy \& Lemeshow, 2008). Thus, one needs larger publications sets to obtain results which might be also valid for neighboring years.

\section{$4 \quad$ Results}

In section 4.1 we compare the NI with other metrics, namely more simple solutions. Costly generated metrics (as the NI) should not correlate very high with more simple solutions. Otherwise the efforts are not justified. In section 4.2 we recommend to complement the size-dependent results of the NI with size-independent results. For example, the Leiden Ranking (www.leidenranking.com) also provides both perspectives. The size-dependent results are mainly caused by the total publication output of a country or institution. 


\subsection{The comparison of NI with other metrics}

The NPG made significant efforts to generate the NI. Two panels have been constituted which have selected the reputable journals. Further, a comprehensive survey has been performed to validate the selection of the panels. These huge efforts are justified only if the NI does not correlate with simpler solutions (metrics). In case of high correlations, one could question these efforts. In this study, we produced three metrics on the country level which are relatively easy to produce.

(1) Total number of papers (Np). Here, a country's number of papers with the WoS document type "article" is counted. For some journals, the NPG selects some articles as primary research articles. This is not reproducible in an automated manner in our database. We consistently obtain too high values for the AC, but we obtain a nearly perfect correlation $\left(r^{2}=0.9985\right)$ between our AC and the official AC by the NPG.

(2) AvgAC: We generated five different random NIs. From each journal in the WoS which published papers in $2014(\mathrm{~N}=12102), 68$ journals were randomly selected. This procedure was repeated five times, resulting in five different (random) ACs for each country. This procedure gave rise to five random NIs with five different (random) ACs for each country. We computed the mean value over the five random ACs which yielded our (random) AvgAC.

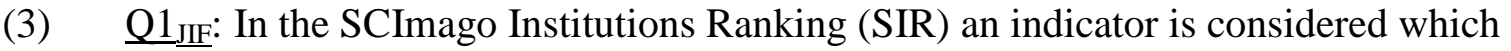
reflects the reputation of the journals in which an institution has published. Q1 is the ratio of papers that an institution publishes in the most influential scholarly journals of the world. The most influential journals are those which ranked in the first quartile $(25 \%)$ of their subject areas (journal sets) as ordered by the SCImago Journal Rank (SJR) indicator (Gonzalez-Pereira, Guerrero-Bote, \& Moya-Anegon, 2010).

The Q1 indicator is a size-independent indicator. In order to produce a size-dependent indicator for this study, which can be correlated with the other size-dependent 
indicators, we identified those papers for a country published in a first quartile ranked journal. Different from the SCImago Institutions Ranking, we used the Journal Impact Factor (JIF) instead of the SJR to select the journals belonging to the first quartile of their subject areas (Pudovkin \& Garfield, 2004). Thus, we name the indicator Q1 $1_{\text {JIF. }}$. Table 1 presents the AC, FC, and WFC values of the NI for the year 2014. Additionally, the Np, Q1 $1_{\mathrm{JIF}}$, and (random) AvgAC are included. For every indicator the corresponding rank numbers were generated. As the results in the table show the indicators lead to the same or similar ranking positions for several countries. For example, the USA and China are at the top positions independent of the used indicators. UK takes up the third or fourth position. However, it is also visible that the ranking positions of many countries differ to a larger extent. For example, Switzerland has the $18^{\text {th }}$ position if the countries are ranked according to the number of papers or random AvgAC. However, the country (significantly) improved its positions if the official NI indicators or the $\mathrm{Q} 1_{\mathrm{JIF}}$ indicator is used.

Since the rank columns in Table 1 do not offer a clear picture of the relationship between the different indicators, we calculated correlation coefficients. 
Table 1: Total number of papers (Np), Q1 $\mathrm{JIF}^{*}$, AvgAC, AC, FC, and WFC for countries in decreasing order of WFC. The rank positions for every country are added based on orderings by the different indicators.

\begin{tabular}{|c|c|c|c|c|c|c|c|c|c|c|c|c|}
\hline Country & $\begin{array}{l}\text { Total } \\
\text { number } \\
\text { of } \\
\text { papers } \\
(\mathrm{Np})\end{array}$ & $\begin{array}{l}\text { Rank } \\
\mathrm{Np}\end{array}$ & $\mathrm{Q}_{\mathrm{JIF}}{ }^{*}$ & $\begin{array}{l}\text { Rank } \\
\text { Q1 }{ }_{\text {JIF }}\end{array}$ & $\begin{array}{l}\operatorname{AvgA} \\
C\end{array}$ & $\begin{array}{l}\text { Rank } \\
\text { AvgA } \\
\text { C }\end{array}$ & $\mathrm{AC}$ & $\begin{array}{l}\text { Rank } \\
\text { AC }\end{array}$ & $\mathrm{FC}$ & $\begin{array}{l}\text { Rank } \\
\text { FC }\end{array}$ & WFC & $\begin{array}{l}\text { Rank } \\
\text { WFC }\end{array}$ \\
\hline $\begin{array}{l}\text { United States of } \\
\text { America (USA) }\end{array}$ & 365437 & 1 & 201555 & 1 & 2189 & 1 & 26631 & 1 & $\begin{array}{r}19765.0 \\
8\end{array}$ & 1 & $\begin{array}{r}17931.8 \\
5\end{array}$ & 1 \\
\hline China & 215731 & 2 & 90233 & 2 & 1011.8 & 2 & 8632 & 2 & 6323.43 & 2 & 6032.52 & 2 \\
\hline Germany & 98154 & 4 & 53002 & 4 & 582 & 3 & 8576 & 3 & 4561.71 & 3 & 4016.03 & 3 \\
\hline United Kingdom (UK) & 102766 & 3 & 56942 & 3 & 559.2 & 4 & 7590 & 4 & 3802.69 & 4 & 3250.06 & 4 \\
\hline Japan & 76638 & 5 & 32281 & 7 & 347.8 & 7 & 4973 & 6 & 3428.46 & 5 & 3198.73 & 5 \\
\hline France & 68382 & 6 & 37602 & 5 & 320 & 9 & 5241 & 5 & 2586.78 & 6 & 2220.89 & 6 \\
\hline Canada & 60340 & 7 & 32401 & 6 & 370.4 & 6 & 3224 & 7 & 1659.27 & 7 & 1488.07 & 7 \\
\hline Switzerland & 25979 & 18 & 15729 & 14 & 138.2 & 18 & 2709 & 10 & 1371.36 & 9 & 1287.8 & 8 \\
\hline South Korea & 50951 & 11 & 19730 & 12 & 287.4 & 11 & 1966 & 13 & 1232.24 & 11 & 1167.49 & 9 \\
\hline Spain & 53876 & 9 & 28237 & 9 & 303 & 10 & 2896 & 9 & 1349.39 & 10 & 1090.7 & 10 \\
\hline Italy & 58707 & 8 & 29305 & 8 & 372.2 & 5 & 3051 & 8 & 1403.6 & 8 & 1046.92 & 11 \\
\hline Australia & 50495 & 12 & 26740 & 10 & 327.4 & 8 & 2497 & 11 & 1145.32 & 12 & 951.22 & 12 \\
\hline India & 51751 & 10 & 16200 & 13 & 253.2 & 12 & 1483 & 14 & 1029.92 & 13 & 921.77 & 13 \\
\hline Netherlands & 35394 & 14 & 21666 & 11 & 203.8 & 14 & 2188 & 12 & 902.53 & 14 & 756.33 & 14 \\
\hline Singapore & 11287 & 30 & 6732 & 22 & 56 & 33 & 873 & 21 & 521.4 & 17 & 520.6 & 15 \\
\hline Sweden & 23716 & 20 & 13463 & 15 & 123.8 & 21 & 1407 & 15 & 570.81 & 15 & 514.55 & 16 \\
\hline Israel & 12491 & 26 & 6604 & 23 & 72.4 & 26 & 1012 & 19 & 546.67 & 16 & 492.44 & 17 \\
\hline Taiwan & 27586 & 16 & 13043 & 16 & 126.2 & 20 & 887 & 20 & 520.18 & 18 & 481.36 & 18 \\
\hline Russia & 28981 & 15 & 6342 & 24 & 215 & 13 & 1145 & 16 & 451.61 & 19 & 370.08 & 19 \\
\hline Belgium & 19704 & 22 & 10839 & 18 & 96.6 & 23 & 1082 & 17 & 426.9 & 20 & 348.91 & 20 \\
\hline Denmark & 14944 & 23 & 8861 & 19 & 102.8 & 22 & 1036 & 18 & 363.1 & 21 & 321.26 & 21 \\
\hline
\end{tabular}




\begin{tabular}{|c|c|c|c|c|c|c|c|c|c|c|c|c|}
\hline Austria & 13384 & 24 & 7281 & 20 & 80 & 24 & 856 & 22 & 350.86 & 22 & 318.98 & 22 \\
\hline Brazil & 38309 & 13 & 11791 & 17 & 175.2 & 15 & 715 & 24 & 315.22 & 23 & 237.01 & 23 \\
\hline Poland & 22872 & 21 & 6979 & 21 & 140.4 & 17 & 685 & 25 & 275.58 & 24 & 209.69 & 24 \\
\hline Finland & 11348 & 29 & 6207 & 26 & 67.6 & 28 & 590 & 26 & 224.32 & 25 & 194.97 & 25 \\
\hline Norway & 11443 & 28 & 6164 & 27 & 54.2 & 38 & 414 & 29 & 160.37 & 28 & 149.77 & 26 \\
\hline Czech Republic & 10602 & 31 & 4211 & 31 & 56.8 & 32 & 372 & 32 & 161.07 & 27 & 126.33 & 27 \\
\hline Portugal & 12696 & 25 & 6150 & 28 & 63 & 29 & 416 & 28 & 143.68 & 30 & 117.45 & 28 \\
\hline Ireland & 7302 & 40 & 3889 & 35 & 44.6 & 41 & 331 & 33 & 125.92 & 32 & 113.91 & 29 \\
\hline Argentina & 8454 & 36 & 3485 & 36 & 38.6 & 43 & 321 & 34 & 142.47 & 31 & 98.58 & 30 \\
\hline New Zealand & 8373 & 37 & 4197 & 32 & 55.6 & 35 & 275 & 37 & 102.96 & 35 & 95.69 & 31 \\
\hline Chile & 6380 & 43 & 2724 & 39 & 68.6 & 27 & 856 & 23 & 192.35 & 26 & 95.12 & 32 \\
\hline Greece & 10096 & 33 & 4494 & 30 & 58.2 & 31 & 319 & 35 & 118.03 & 34 & 91.76 & 33 \\
\hline Mexico & 11681 & 27 & 4035 & 34 & 74.2 & 25 & 391 & 30 & 146.56 & 29 & 84.6 & 34 \\
\hline South Africa & 10301 & 32 & 4104 & 33 & 54.8 & 37 & 417 & 27 & 122.16 & 33 & 81.55 & 35 \\
\hline Turkey & 26206 & 17 & 5518 & 29 & 134 & 19 & 236 & 38 & 97.53 & 36 & 79.24 & 36 \\
\hline Hungary & 6312 & 44 & 2613 & 40 & 50.8 & 39 & 276 & 36 & 96.2 & 37 & 78.48 & 37 \\
\hline Saudi Arabia & 9061 & 35 & 3191 & 37 & 55.8 & 34 & 384 & 31 & 80.37 & 39 & 76.63 & 38 \\
\hline Iran & 25824 & 19 & 6244 & 25 & 153.2 & 16 & 147 & 40 & 81.03 & 38 & 67.87 & 39 \\
\hline Ukraine & 4869 & 46 & 1255 & 47 & 31.8 & 44 & 173 & 39 & 50.5 & 40 & 37.06 & 40 \\
\hline Slovenia & 3888 & 47 & 1478 & 44 & 22.4 & 48 & 106 & 41 & 37.89 & 41 & 36.36 & 41 \\
\hline Thailand & 6583 & 41 & 2389 & 41 & 27.4 & 46 & 92 & 43 & 24.98 & 43 & 22.68 & 42 \\
\hline Estonia & 1744 & 53 & 799 & 51 & 9.2 & 53 & 92 & 44 & 27.42 & 42 & 22.31 & 43 \\
\hline Romania & 8246 & 38 & 2109 & 43 & 40.4 & 42 & 79 & 46 & 24.66 & 44 & 21.41 & 44 \\
\hline Croatia & 3512 & 48 & 1024 & 49 & 17.8 & 49 & 102 & 42 & 23.3 & 47 & 17.56 & 45 \\
\hline Serbia & 5105 & 45 & 1441 & 45 & 26 & 47 & 55 & 52 & 24.62 & 46 & 17 & 46 \\
\hline Lithuania & 1996 & 52 & 519 & 55 & 8.8 & 54 & 58 & 50 & 24.62 & 45 & 16.85 & 47 \\
\hline Malaysia & 9282 & 34 & 2971 & 38 & 59.4 & 30 & 53 & 53 & 15.81 & 50 & 15.81 & 48 \\
\hline Egypt & 7932 & 39 & 2160 & 42 & 55.4 & 36 & 87 & 45 & 14.69 & 52 & 14.32 & 49 \\
\hline Slovakia & 3219 & 50 & 979 & 50 & 15.8 & 50 & 63 & 49 & 21 & 48 & 14.15 & 50 \\
\hline
\end{tabular}




\begin{tabular}{|c|c|c|c|c|c|c|c|c|c|c|c|c|}
\hline Pakistan & 6446 & 42 & 1411 & 46 & 28.4 & 45 & 42 & 55 & 17.04 & 49 & 12.83 & 52 \\
\hline United Arab Emirates & 1456 & 55 & 583 & 54 & 11.2 & 52 & 49 & 54 & 11.53 & 55 & 9.37 & 54 \\
\hline Colombia & 3422 & 49 & 1210 & 48 & 15.2 & 51 & 56 & 51 & 11.72 & 54 & 9.36 & 55 \\
\hline Bulgaria & 2302 & 51 & 707 & 52 & 46.8 & 40 & 63 & 48 & 14.83 & 51 & 8.59 & 57 \\
\hline Indonesia & 1563 & 54 & 644 & 53 & 6.4 & 55 & 30 & 59 & 6.72 & 59 & 5.92 & 59 \\
\hline
\end{tabular}

Note. * Q1 $1_{\mathrm{JIF}}$ values are from 2013 and not from 2014. The results of Lopez-Abente and Munoz-Tinoco (2005) and Tsigilis, Grouios,

Tsorbatzoudis, and Koidou (2010) show that journals' JIFs remained relatively stable over the years. 
Based on the indicator values in Table 1, we calculated Spearman's rank correlation coefficients. This coefficient is a descriptive statistical measure which represents the degree of relationship between two indicators. A positive correlation points to a monotonic increase, that means the increase in the value of one indicator is always accompanied by an increase in the value of the other indicator (Sheskin, 2007). The results of the correlations are shown in the correlation matrix of Table 2 . All correlation coefficients are at least at $r_{s}=.88$. When we interpret the coefficients against the backdrop of Cohen (1988), we can conclude that the coefficients are much larger than typical and on a very high level (see also Kraemer et al., 2003).

The most important NI indicator is the WFC. This indicator is mainly used by the NPG to rank institutions or countries. WFC shows the highest correlations with the other NI indicators ( $\mathrm{r}_{\mathrm{s}}=.98$ for the $\mathrm{AC}$ and $\mathrm{r}_{\mathrm{s}}=.99$ for the $\left.\mathrm{FC}\right)$. A similar high correlation is pointed out for the $\mathrm{Q} 1_{\mathrm{JIF}}$ indicator $\left(\mathrm{r}_{\mathrm{s}}=.96\right)$. The correlations with the total number of papers and the (random) AvgAC are somewhat lower with $r_{s}=.91$ and $r_{s}=.88$, but still much higher than one would expect.

Table 2: Correlations between total number of papers (Np), Q1 $1_{\mathrm{JIF}}, \mathrm{AvgAC}, \mathrm{AC}, \mathrm{FC}$, and WFC

\begin{tabular}{|l|r|r|r|r|r|r|}
\hline & \multicolumn{1}{|l|}{ Np } & \multicolumn{1}{l|}{ Q1 $1_{\text {JIF }}$} & AvgAC & AC & FC & WFC \\
\hline Np & 1 & & & & & \\
\hline Q1 JIF & 0.97 & 1 & & & & \\
\hline Avg_AC & 0.97 & 0.95 & 1 & & & \\
\hline AC & 0.90 & 0.95 & 0.90 & 1 & & \\
\hline FC & 0.91 & 0.96 & 0.89 & 0.99 & 1 & \\
\hline WFC & 0.91 & 0.96 & 0.88 & 0.98 & 0.99 & 1 \\
\hline
\end{tabular}




\subsection{Size-independent and size-dependent NI indicators}

In the previous section, we have shown that the different NI variants correlate much higher than typical with the mere number of papers on the country level. This result points out that the NI variants are size-dependent indicators. Thus, we recommend to complement the size-dependent NI indicators with size-independent NI indicators. Already in Haunschild \& Bornmann (2015), we recommended this additional perspective and gave the following supporting example: The NI ranks the Chinese Academy of Sciences (CAS) before Harvard University with 2,661 papers from CAS and 2,555 papers from Harvard in 2013. Considering the full publication output of both institutes in 2013 (31,428 for CAS and 17,836 for Harvard), we see that in relative terms Harvard (14\% of Harvard papers in the NI) ranks higher than the CAS ( $8 \%$ of CAS papers in the NI).

The CWTS justifies its presentation of size-independent indicators (besides sizedependent indicators) in the Leiden ranking as follows: "In the case of size-dependent indicators, universities with a larger publication output tend to perform better than universities with a smaller publication output. Size-independent indicators have been corrected for the size of the publication output of a university. So when size-independent indicators are used, both larger and smaller universities may perform well" (http://www.leidenranking.com/methodology/indicators\#sthash.52ZO1Kmm.dpuf). On the country-level, many small countries have no way of publishing the same (or larger) number of papers in NI journals as large countries. For example, the USA published $n=26,631$ papers in journals considered in the NI (see Table 1). Switzerland has a total publication output of $\mathrm{n}=25,979$. Since the papers published in NI journals cannot exceed the total publication output of a country, Switzerland could never reach the top position in the AC, FC, or WFC ranking. 
Table 3: Number of papers (Np), AC, RelAC, RelQ1 $1_{\mathrm{JIF}}$, and RelAvgAC by country. The rank positions for every country are added based on orderings by the different indicators. The table is sorted in decreasing order by RelAC.

\begin{tabular}{|c|c|c|c|c|c|c|c|c|c|}
\hline Country & $\mathrm{Np}$ & $\mathrm{AC}$ & $\begin{array}{l}\text { Rank } \\
\text { AC }\end{array}$ & RelAC & $\begin{array}{l}\text { Rank } \\
\text { RelAC }\end{array}$ & RelQ1 $_{\mathrm{JIF}}$ & $\begin{array}{l}\text { Rank } \\
\text { RelQ1 }\end{array}$ & RelAvgAC & \begin{tabular}{|l|} 
Rank \\
RelAvgAC \\
\end{tabular} \\
\hline Chile & 6380 & 856 & 23 & 13.42 & 1 & 42.70 & 25 & 1.08 & 2 \\
\hline Switzerland & 25979 & 2709 & 10 & 10.43 & 2 & 60.55 & 2 & 0.53 & 32 \\
\hline Germany & 98154 & 8576 & 3 & 8.74 & 3 & 54.00 & 12 & 0.59 & 22 \\
\hline Israel & 12491 & 1012 & 19 & 8.10 & 4 & 52.87 & 17 & 0.58 & 23 \\
\hline Singapore & 11287 & 873 & 21 & 7.73 & 5 & 59.64 & 3 & 0.50 & 39 \\
\hline France & 68382 & 5241 & 5 & 7.66 & 6 & 54.99 & 9 & 0.47 & 46 \\
\hline United Kingdom (UK) & 102766 & 7590 & 4 & 7.39 & 7 & 55.41 & 6 & 0.54 & 29 \\
\hline United States of America (USA) & 365437 & 26631 & 1 & 7.29 & 8 & 55.15 & 7 & 0.60 & 18 \\
\hline Denmark & 14944 & 1036 & 18 & 6.93 & 9 & 59.29 & 4 & 0.69 & 7 \\
\hline Japan & 76638 & 4973 & 6 & 6.49 & 10 & 42.12 & 26 & 0.45 & 50 \\
\hline Austria & 13384 & 856 & 22 & 6.40 & 11 & 54.40 & 11 & 0.60 & 19 \\
\hline Netherlands & 35394 & 2188 & 12 & 6.18 & 12 & 61.21 & 1 & 0.58 & 26 \\
\hline Sweden & 23716 & 1407 & 15 & 5.93 & 13 & 56.77 & 5 & 0.52 & 34 \\
\hline Belgium & 19704 & 1082 & 17 & 5.49 & 14 & 55.01 & 8 & 0.49 & 41 \\
\hline Spain & 53876 & 2896 & 9 & 5.38 & 15 & 52.41 & 18 & 0.56 & 28 \\
\hline Canada & 60340 & 3224 & 7 & 5.34 & 16 & 53.70 & 14 & 0.61 & 15 \\
\hline Estonia & 1744 & 92 & 44 & 5.28 & 17 & 45.81 & 23 & 0.53 & 33 \\
\hline Finland & 11348 & 590 & 26 & 5.20 & 18 & 54.70 & 10 & 0.60 & 20 \\
\hline Italy & 58707 & 3051 & 8 & 5.20 & 19 & 49.92 & 20 & 0.63 & 13 \\
\hline Australia & 50495 & 2497 & 11 & 4.95 & 20 & 52.96 & 16 & 0.65 & 10 \\
\hline Ireland & 7302 & 331 & 33 & 4.53 & 21 & 53.26 & 15 & 0.61 & 17 \\
\hline Hungary & 6312 & 276 & 36 & 4.37 & 22 & 41.40 & 28 & 0.80 & 3 \\
\hline
\end{tabular}




\begin{tabular}{|c|c|c|c|c|c|c|c|c|c|}
\hline Saudi Arabia & 9061 & 384 & 31 & 4.24 & 23 & 35.22 & 38 & 0.62 & 14 \\
\hline South Africa & 10301 & 417 & 27 & 4.05 & 24 & 39.84 & 32 & 0.53 & 31 \\
\hline China & 215731 & 8632 & 2 & 4.00 & 25 & 41.83 & 27 & 0.47 & 45 \\
\hline Russia & 28981 & 1145 & 16 & 3.95 & 26 & 21.88 & 54 & 0.74 & 5 \\
\hline South Korea & 50951 & 1966 & 13 & 3.86 & 27 & 38.72 & 34 & 0.56 & 27 \\
\hline Argentina & 8454 & 321 & 34 & 3.80 & 28 & 41.22 & 29 & 0.46 & 49 \\
\hline Norway & 11443 & 414 & 29 & 3.62 & 29 & 53.87 & 13 & 0.47 & 44 \\
\hline Czech Republic & 10602 & 372 & 32 & 3.51 & 31 & 39.72 & 33 & 0.54 & 30 \\
\hline United Arab Emirates & 1456 & 49 & 54 & 3.37 & 32 & 40.04 & 31 & 0.77 & 4 \\
\hline Mexico & 11681 & 391 & 30 & 3.35 & 33 & 34.54 & 39 & 0.64 & 12 \\
\hline New Zealand & 8373 & 275 & 37 & 3.28 & 34 & 50.13 & 19 & 0.66 & 8 \\
\hline Portugal & 12696 & 416 & 28 & 3.28 & 35 & 48.44 & 21 & 0.50 & 38 \\
\hline Taiwan & 27586 & 887 & 20 & 3.22 & 36 & 47.28 & 22 & 0.46 & 47 \\
\hline Poland & 22872 & 685 & 25 & 2.99 & 38 & 30.51 & 44 & 0.61 & 16 \\
\hline Lithuania & 1996 & 58 & 50 & 2.91 & 39 & 26.00 & 49 & 0.44 & 52 \\
\hline Croatia & 3512 & 102 & 42 & 2.90 & 40 & 29.16 & 46 & 0.51 & 37 \\
\hline India & 51751 & 1483 & 14 & 2.87 & 41 & 31.30 & 41 & 0.49 & 43 \\
\hline Bulgaria & 2302 & 63 & 49 & 2.74 & 42 & 30.71 & 43 & 2.03 & 1 \\
\hline Slovenia & 3888 & 106 & 41 & 2.73 & 43 & 38.01 & 35 & 0.58 & 25 \\
\hline Slovakia & 3219 & 63 & 48 & 1.96 & 44 & 30.41 & 45 & 0.49 & 40 \\
\hline Indonesia & 1563 & 30 & 59 & 1.92 & 45 & 41.20 & 30 & 0.41 & 55 \\
\hline Brazil & 38309 & 715 & 24 & 1.87 & 46 & 30.78 & 42 & 0.46 & 48 \\
\hline Colombia & 3422 & 56 & 51 & 1.64 & 47 & 35.36 & 37 & 0.44 & 51 \\
\hline Thailand & 6583 & 92 & 43 & 1.40 & 48 & 36.29 & 36 & 0.42 & 54 \\
\hline Egypt & 7932 & 87 & 45 & 1.10 & 49 & 27.23 & 48 & 0.70 & 6 \\
\hline Serbia & 5105 & 55 & 52 & 1.08 & 50 & 28.23 & 47 & 0.51 & 36 \\
\hline
\end{tabular}




\begin{tabular}{|l|r|c|c|r|r|r|r|r|r|}
\hline Turkey & 26206 & 236 & 38 & 0.90 & 52 & 21.06 & 55 & 0.51 & 35 \\
\hline Pakistan & 6446 & 42 & 55 & 0.65 & 53 & 21.89 & 53 & 0.44 & 53 \\
\hline Malaysia & 9282 & 53 & 53 & 0.57 & 54 & 32.01 & 40 & 0.64 & 11 \\
\hline Iran & 25824 & 147 & 40 & 0.57 & 55 & 24.18 & 52 & 0.59 & 21 \\
\hline
\end{tabular}


Table 3 shows the size-independent AC values (RelAC) for the different countries whereas the AC values have been divided by the total number of papers of the specific country and multiplied with 100 in order to obtain percentages:

$$
\operatorname{RelAC}=\mathrm{AC} / \mathrm{Np} * 100
$$

For comparison, analogous size-independent values for the $\mathrm{Q}_{\mathrm{JIF}}\left(\mathrm{RelQ} 1_{\mathrm{JIF}}\right)$ and AvgAC (RelAvgAC) indicators have been added. We could not calculate relative FC and WFC indicators, because we are not able to reproduce this variant of fractional counting based on our in-house database. As the results in Table 3 show (expectedly) the sizeindependent AC variant leads to top positions for smaller countries, like Chile or Switzerland. UK and USA are on positions seven and eight. Similar results are visible for RelQ1 $1_{\mathrm{JIF}}$ and RelAvgAC: RelQ1 $1_{\mathrm{JIF}}$ leads to top positions for the Netherlands, Switzerland, and Singapore and RelAvgAC puts Bulgaria, Chile, and Hungary on top positions. Whereas the top positions based on RelQ1 $1_{\mathrm{JIF}}$ are reasonable (Netherlands, Switzerland, and Singapore are known as high performing small countries), the results based on RelAvgAc (Bulgaria and Hungary) seem questionable.

Similar to section 4.1, we calculated Spearman's rank correlation coefficients to compare AC and the different size-independent indicators. The correlation between AC and RelAc is $r_{s}=0.76$. Since this correlation coefficient is definitely lower than the coefficients in Table 2, the relative variant seems to be an informative additional indicator to the AC (Cohen, 1988; Kraemer et al., 2003). RelQ1 $1_{\mathrm{JIF}}$ correlates on a similar level with RelAc $\left(\mathrm{r}_{\mathrm{s}}=0.82\right)$ and definitely less with AC and $\left(r_{s}=0.64\right)$. However, we obtain significantly lower coefficients for the correlations with RelAvgAC (between $r_{s}=0.06$ and $r_{s}=0.23$ ). As the top country positions for the RelAvgAC already revealed, the generally low coefficients point to less conforming results with the other indicators (with the size-dependent AC as well as the size-independent RelAC and RelQ1 $\left.1_{\mathrm{JIF}}\right)$ and questions the validity of this indicator. 
Table 4: Correlations between AC, RelAC, and RelQ1 $1_{\mathrm{JIF}}$

\begin{tabular}{|l|r|r|r|r|}
\hline & \multicolumn{1}{|r|}{ AC } & RelAC & RelQ1 $1_{\text {JIF }}$ & RelAvgAC \\
\hline AC & 1 & & & \\
\hline RelAC & 0.76 & 1 & & \\
\hline RelQ1 ${ }_{\text {JIF }}$ & 0.64 & 0.82 & 1 & \\
\hline RelAvgAC & 0.08 & 0.23 & 0.06 & 1 \\
\hline
\end{tabular}

The relative indicators RelAC and RelQ1 $1_{\mathrm{JIF}}$ certainly offer an important additional perspective on country performance to $\mathrm{AC}$ and $\mathrm{Q} 1_{\mathrm{JIF}}$. There is also another kind of relative indicators that can be informative: Indicators obtained by normalizing for the worldwide production, specifically $\mathrm{AC}$ divided by the sum of $\mathrm{AC}(\mathrm{Re}$ Sum $\mathrm{AC})$ and $\mathrm{Q} 1_{\mathrm{JIF}}$ divided by the sum of $\mathrm{Q} 1_{\mathrm{JIF}}\left(\right.$ RelSumQ1 $\left.1_{\mathrm{JIF}}\right)$. Here, AC and Q1 $1_{\mathrm{JIF}}$, respectively, are divided by the sum over all countries (AC or Q1 $\mathrm{JIF}$, respectively). Finally, these indicators are multiplied by 100 in order to obtain percentages:

$$
\begin{aligned}
& \text { RelSumAC }=\mathrm{AC} / \sum \mathrm{AC} * 100 \\
& \text { RelSumQ1 }_{\mathrm{JIF}}=\mathrm{Q} 1_{\mathrm{JIF}} / \sum \mathrm{Q} 1_{\mathrm{JIF}} * 100
\end{aligned}
$$

These indicators can answer the question: Among all the papers published in reputable journals worldwide (measured by AC or Q1 $1_{\mathrm{JIF}}$ ), how many of them come from a specific country? Note that RelSumAC and RelSumQ $1_{\mathrm{JIF}}$ offer a relative perspective (relative to the world), but the indicators are size-dependent. Since ranks based on these indicators would lead to the same country positions as in Table $1\left(\mathrm{AC}\right.$ and $\left.\mathrm{Q} 1_{\mathrm{JIF}}\right)$, we present in Table 5 the indicator values only. As the results in the table show the USA is the largest producer of papers published in reputable journals with $23.87 \%$ (RelSumQ1 $1_{\mathrm{JIF}}$ ) and 27.04\% (RelSumAC). 
Table 5: RelSumAC and RelSumQ1 $1_{\mathrm{JIF}}$ by country (in percent). The table is sorted in decreasing order by RelSumAC.

\begin{tabular}{|c|c|c|c|c|}
\hline Country & Q1 & $\mathbf{A C}$ & RelSumQ1 $_{\text {JIF }}$ & RelSumAC \\
\hline United States of America (USA) & 201555 & 26631 & 23.87 & 27.04 \\
\hline China & 90233 & 8632 & 10.69 & 8.76 \\
\hline Germany & 53002 & 8576 & 6.28 & 8.71 \\
\hline United Kingdom (UK) & 56942 & 7590 & 6.74 & 7.71 \\
\hline France & 37602 & 5241 & 4.45 & 5.32 \\
\hline Japan & 32281 & 4973 & 3.82 & 5.05 \\
\hline Canada & 32401 & 3224 & 3.84 & 3.27 \\
\hline Italy & 29305 & 3051 & 3.47 & 3.10 \\
\hline Spain & 28237 & 2896 & 3.34 & 2.94 \\
\hline Switzerland & 15729 & 2709 & 1.86 & 2.75 \\
\hline Australia & 26740 & 2497 & 3.17 & 2.54 \\
\hline Netherlands & 21666 & 2188 & 2.57 & 2.22 \\
\hline South Korea & 19730 & 1966 & 2.34 & 2.00 \\
\hline India & 16200 & 1483 & 1.92 & 1.51 \\
\hline Sweden & 13463 & 1407 & 1.59 & 1.43 \\
\hline Russia & 6342 & 1145 & 0.75 & 1.16 \\
\hline Belgium & 10839 & 1082 & 1.28 & 1.10 \\
\hline Denmark & 8861 & 1036 & 1.05 & 1.05 \\
\hline Israel & 6604 & 1012 & 0.78 & 1.03 \\
\hline Taiwan & 13043 & 887 & 1.54 & 0.90 \\
\hline Singapore & 6732 & 873 & 0.80 & 0.89 \\
\hline Austria & 7281 & 856 & 0.86 & 0.87 \\
\hline Chile & 2724 & 856 & 0.32 & 0.87 \\
\hline Brazil & 11791 & 715 & 1.40 & 0.73 \\
\hline Poland & 6979 & 685 & 0.83 & 0.70 \\
\hline Finland & 6207 & 590 & 0.74 & 0.60 \\
\hline South Africa & 4104 & 417 & 0.49 & 0.42 \\
\hline Portugal & 6150 & 416 & 0.73 & 0.42 \\
\hline Norway & 6164 & 414 & 0.73 & 0.42 \\
\hline Mexico & 4035 & 391 & 0.48 & 0.40 \\
\hline Saudi Arabia & 3191 & 384 & 0.38 & 0.39 \\
\hline Czech Republic & 4211 & 372 & 0.50 & 0.38 \\
\hline Ireland & 3889 & 331 & 0.46 & 0.34 \\
\hline Argentina & 3485 & 321 & 0.41 & 0.33 \\
\hline Greece & 4494 & 319 & 0.53 & 0.32 \\
\hline Hungary & 2613 & 276 & 0.31 & 0.28 \\
\hline New Zealand & 4197 & 275 & 0.50 & 0.28 \\
\hline Turkey & 5518 & 236 & 0.65 & 0.24 \\
\hline Ukraine & 1255 & 173 & 0.15 & 0.18 \\
\hline Iran & 6244 & 147 & 0.74 & 0.15 \\
\hline Slovenia & 1478 & 106 & 0.18 & 0.11 \\
\hline Croatia & 1024 & 102 & 0.12 & 0.10 \\
\hline
\end{tabular}




\begin{tabular}{|l|r|r|r|r|}
\hline Estonia & 799 & 92 & 0.09 & 0.09 \\
\hline Thailand & 2389 & 92 & 0.28 & 0.09 \\
\hline Egypt & 2160 & 87 & 0.26 & 0.09 \\
\hline Romania & 2109 & 79 & 0.25 & 0.08 \\
\hline Iceland & 515 & 65 & 0.06 & 0.07 \\
\hline Bulgaria & 707 & 63 & 0.08 & 0.06 \\
\hline Slovakia & 979 & 63 & 0.12 & 0.06 \\
\hline Lithuania & 519 & 58 & 0.06 & 0.06 \\
\hline Colombia & 1210 & 56 & 0.14 & 0.06 \\
\hline Serbia & 1441 & 55 & 0.17 & 0.06 \\
\hline Malaysia & 2971 & 53 & 0.35 & 0.05 \\
\hline United Arab Emirates & 583 & 49 & 0.07 & 0.05 \\
\hline Pakistan & 1411 & 42 & 0.17 & 0.04 \\
\hline Luxembourg & 471 & 35 & 0.06 & 0.04 \\
\hline Qatar & 442 & 35 & 0.05 & 0.04 \\
\hline Panama & 199 & 32 & 0.02 & 0.03 \\
\hline Armenia & 329 & 30 & 0.04 & 0.03 \\
\hline Indonesia & 644 & 30 & 0.08 & 0.03 \\
\hline Total & 844419 & 98497 & 100.00 & 100.00 \\
\hline
\end{tabular}

\section{Discussion}

According to Osterloh and Frey (2014), there are four reasons why "rankings are deemed to be necessary. First, it is argued that because of the high specialization of research and the lack of expertise in areas that are different from the own research field, it is efficient to rely on research rankings ... Second, research rankings fuel competition among scholars, lead to more and better research, and promote what is called an 'entrepreneurial university' ... Third, research rankings give the public a transparent picture of scholarly activity. They make scientific merits visible to people who have no special knowledge of the field like politicians, public officials, deans, university administrators, and journalists ... Fourth, academic rankings make universities and departments more accountable for their use of public money" (Osterloh \& Frey, 2014, p. 2). However, university rankings have always been heavily criticized (Huang, 2012; Mutz \& Daniel, in press; Schmoch, 2015). For example, it is 
criticized that different indicator values are weighted in a specific way in order to compute a sum score and that the weighting is not appropriately justified.

The NI does not use a mix of different indicators to compute a sum score. It is based on the number of papers (fractionally counted) published in reputable journals. Thus, the NI provides a ranking of institutions and countries based on a small sub-set of bibliometric data only. Starting from two short comments on the NI (Haunschild \& Bornmann, 2015a, 2015b), we undertook an empirical analysis of the index using comprehensive country data. The analysis is based on data from the MPDL in-house database (which is based on WoS data). In a first step of analysis, we correlated the NI with other metrics which are simpler to generate than the NI. The resulting very large correlation coefficients point out that the NI produces very similar results as simpler solutions. Thus, the use of the NI is questioned by the empirical results. For example, the NI could be replaced by the $\mathrm{Q} 1_{\mathrm{JIF}}$ indicator (which is used in the SIR and excellencemapping.net in a similar form, see Bornmann, Stefaner, de Moya Anegón, \& Mutz, 2014) and also measures the amount of output published in high-quality journals. In a second step of analysis, two relative variants of the NI have been generated: one variant is size-independent (RelAC and RelQ1 $1_{\mathrm{JIF}}$ ) and one variant is size-dependent (RelSumAC and RelSumQ1 $1_{\mathrm{JF}}$ ). The size-dependent variant produces the same country ranks as the original AC and the Q1 $1_{\mathrm{JIF}}$. Therefore, we recommend that the relative and sizeindependent variants (RelAC and RelQ1 $1_{\mathrm{JIF}}$ ) should be additionally presented by the NPG along with the fractionally counted versions RelFC and RelWFC. The size-dependent NI indicators favor large countries (or institutions) and the top-performing small countries (or institutions) do not come into the picture.

According to Campbell and Grayson (2015), the "NPG actively seeks constructive feedback from the researcher community we serve, and our aim is to iterate and improve the Nature Index in response to such feedback” (p. 1831). We hope that our empirical results and recommendations are helpful for the improvement of the NI. 


\section{Acknowledgements}

The bibliometric data used in this paper are from an in-house database developed and maintained by the Max Planck Digital Library (MPDL, Munich) and derived from the Science Citation Index Expanded (SCI-E), Social Sciences Citation Index (SSCI), Arts and Humanities Citation Index (AHCI) prepared by Thomson Reuters (Philadelphia, Pennsylvania, USA). We thank the anonymous reviewers for their constructive comments on the initial version of our manuscript. 


\section{References}

Aguillo, I. F., Bar-Ilan, J., Levene, M., \& Ortega, J. L. (2010). Comparing university rankings. Scientometrics, 85(1), 243-256. doi: DOI 10.1007/s11192-010-0190-z.

Bornmann, L., Stefaner, M., de Moya Anegón, F., \& Mutz, R. (2014). What is the effect of country-specific characteristics on the research performance of scientific institutions? Using multi-level statistical models to rank and map universities and research-focused institutions worldwide. Journal of Informetrics, 8(3), 581-593.

Buela-Casal, G., Gutiérrez-Martínez, O., Bermúdez-Sánchez, M., \& Vadillo-Muñoz, O. (2007). Comparative study of international academic rankings of universities. Scientometrics, 71(3), 349-365.

Campbell, N., \& Grayson, M. (2014). Introducing the index. Nature, 515(7526), S52-S53.

Campbell, N., \& Grayson, M. (2015). A response to 'Discussion about the new Nature Index'. Scientometrics, 102(2), 1831-1833. doi: 10.1007/s11192-014-1516-z.

Cohen, J. (1988). Statistical power analysis for the behavioral sciences (2nd ed.). Hillsdale, NJ, USA: Lawrence Erlbaum Associates, Publishers.

Dill, D. D., \& Soo, M. (2005). Academic quality, league tables, and public policy: A crossnational analysis of university ranking systems. Higher Education, 49(4), 495-533.

Gonzalez-Pereira, B., Guerrero-Bote, V. P., \& Moya-Anegon, F. (2010). A new approach to the metric of journals' scientific prestige: the SJR indicator. Journal of Informetrics, 4(3), 379-391. doi: 10.1016/j.joi.2010.03.002.

Haunschild, R., \& Bornmann, L. (2015a). Criteria for Nature Index questioned. Nature, 517(7532), 21.

Haunschild, R., \& Bornmann, L. (2015b). Discussion about the new Nature Index. Scientometrics, 102(2), 1829-1830. doi: 10.1007/s11192-014-1505-2.

Huang, M. H. (2012). Opening the black box of QS World University Rankings. Research Evaluation, 21(1), 71-78. doi: DOI 10.1093/reseval/rvr003.

Kraemer, H. C., Morgan, G. A., Leech, N. L., Gliner, J. A., Vaske, J. J., \& Harmon, R. J. (2003). Measures of clinical significance. Journal of the American Academy of Child and Adolescent Psychiatry, 42(12), 1524-1529. doi: 10.1097/01.chi.0000091507.46853.d1.

Levy, P. S., \& Lemeshow, S. (2008). Sampling of Populations: Methods and Applications. Hoboken, NJ, USA: Wiley.

Lopez-Abente, G., \& Munoz-Tinoco, C. (2005). Time trends in the impact factor of Public Health journals. BMC Public Health, 5. doi: 10.1186/1471-2458-5-24.

Mutz, R., \& Daniel, H.-D. (in press). What is behind the curtain of the Leiden Ranking? Journal of the Association for Information Science and Technology.

Osterloh, M., \& Frey, B. S. (2014). Ranking Games. Evaluation Review. doi: $10.1177 / 0193841 \times 14524957$.

Pudovkin, A. I., \& Garfield, E. (2004). Rank-normalized impact factor: a way to compare journal performance across subject categories. In J. B. Bryans (Ed.), ASIST 2004: Proceedings of the 67th Asis\&T Annual Meeting, Vol 41, 2004: Managing and Enhancing Information: Cultures and Conflicts (Vol. 41, pp. 507-515). Medford: Information Today Inc.

Rauhvargers, A. (2011). Global university rankings and their impact. Brussels, Belgium: European University Association (EUA).

Safón, V. (2013). What do global university rankings really measure? The search for the X factor and the X entity. Scientometrics, 97(2), 223-244. doi: 10.1007/s11192-0130986-8. 
Schmoch, U. (2015). The Informative Value of International University Rankings: Some Methodological Remarks. In I. M. Welpe, J. Wollersheim, S. Ringelhan \& M.

Osterloh (Eds.), Incentives and Performance (pp. 141-154): Springer International Publishing.

Sheskin, D. (2007). Handbook of parametric and nonparametric statistical procedures (4th ed.). Boca Raton, FL, USA: Chapman \& Hall/CRC.

Tsigilis, N., Grouios, G., Tsorbatzoudis, H., \& Koidou, I. (2010). Impact factors of the sport sciences journals: Current trends, relative positions, and temporal stability. European Journal of Sport Science, 10(2), 81-90. doi: Pii 919150584

$10.1080 / 17461390903125152$. 